\title{
A Nash bargaining model for simple exchange networks ${ }^{\text {is }}$
}

\author{
Norman Braun ${ }^{\mathrm{a}}$, Thomas Gautschi ${ }^{\mathrm{b}, *}$ \\ a Department of Sociology, University of Munich, Konradstr. 6, 80801 Munich, Germany \\ b Department of Sociology, University of Bern, Lerchenweg 36, 3000 Bern 9, Switzerland
}

\begin{abstract}
Starting from exogenously given negotiation networks, sociological exchange theories explain bilateral divisions of fixed surpluses (e.g., cake, dollar) as consequences of the partners' structural embeddedness. In accordance with the available experimental evidence, we focus on simple exchange networks and present a formal model for predicting profit splits from such structures. In contrast to other approaches, we combine the generalized Nash bargaining solution from game theory with the assumption that both relational features and network positions affect exchange outcomes. The resulting point predictions for profit splits correspond closely with experimental results obtained by Cook et al. [Cook, K.S., Emerson, R.M., Gillmore, M.R., Yamagishi, T., 1983. The distribution of power in exchange networks: theory and experimental results. American Journal of Sociology 89, 275-305], Lovaglia et al. [Lovaglia, M.J., Skvoretz, J., Willer, D., Markovsky, B., 1995. Negotiated exchanges in social networks. Social Forces 74, 123-155], Markovsky et al. [Markovsky, B., Willer, D., Patton, T., 1988. Power relations in exchange networks. American Sociological Review 53, 220-236], Simpson and Willer [Simpson, B., Willer, D., 1999. A new method for finding power structures. In: Willer, D. (Ed.), Network Exchange Theory. Praeger, Westport, CT, pp. 270-284], Skvoretz and Fararo [Skvoretz, J., Fararo, T.J., 1992. Power and network exchange: an essay toward theoretical unification. Social Networks 14, 325-344], Skvoretz and Willer [Skvoretz, J., Willer, D., 1993. Exclusion and power: a test of four theories of power in exchange networks. American Sociological Review 58,
\end{abstract}

\footnotetext{
is An earlier version was presented at the 1999 fall meeting of the section "Model Building and Simulation" of the German Sociological Association in Heidelberg, at a 2002 conference of The Netherlands Institute for Advanced Study in the Humanities and Social Sciences (NIAS) in Wassenaar, and in seminars at Venice International University, Utrecht University, University of Groningen, and the University of Bern.

* Corresponding author.

E-mail addresses: norman.braun@ soziologie.uni-muenchen.de (N. Braun); gautschi@ soz.unibe.ch (T. Gautschi).
} 
801-818] as well as Yamagishi et al. [Yamagishi, T., Gillmore, M.R., Cook, K.S., 1988. Network connections and the distribution of power in exchange networks. American Journal of Sociology 93, 833-851].

(C) 2004 Published by Elsevier B.V.

JEL classification: $\mathrm{C} 71 ; \mathrm{C} 78 ; \mathrm{C} 91$

Keywords: Nash; Model; Network

\section{Introduction}

Employers and employees, lawyers and clients, or business firms often determine their contracts in dyadic negotiations. Sociological exchange theories (see, for overviews, several contributions in Willer, 1999) reflect this pattern - they often explain exchange outcomes as the result of bilateral bargaining on the distribution of a perfectly divisible surplus (e.g., cake, dollar). Following Cook et al. (1983), sociologists usually consider a situation in which a given network structure limits matches between pairs of bargaining partners, propose formal models to predict outcomes of negotiated exchanges, and test those predictions in laboratory experiments. However, there are not just different theories, but also many controversies - a selection of important contributions and discussions includes Bienenstock and Bonacich (1992, 1993, 1997), Bonacich and Bienenstock (1995), Bonacich (1998, 1999), Bonacich and Friedkin (1998), Burke (1997), Friedkin (1992, 1993, 1995), Lovaglia et al. (1995), Markovsky et al. (1993, 1997), Markovsky et al. (1988, 1990), Skvoretz and Fararo (1992), Skvoretz and Lovaglia (1995), Skvoretz and Willer (1991, 1993), Thye et al. (1997), Yamagishi and Cook (1990), Yamagishi et al. (1988) as well as Yamaguchi (1996, 1997, 2000). ${ }^{1}$

Despite their differences, sociological exchange theories have common features. First, practically all theories neglect interindividual heterogeneity (in terms of, e.g., age, education, gender, or wealth) in favor of the effects the given network structure has for exchange outcomes. More precisely, they explain how the structural positions in the bargaining network affect the exchange outcomes between adjacent actors. Power inequalities due to different structural positions manifest themselves in the negotiated distributions of exchange profits.

Second, most theoretical approaches do not account for variations in the value of relationships. That is, there is not necessarily heterogeneity in terms of the size of the cake to be partitioned. And, apart from exceptions (e.g., Bonacich and Friedkin, 1998; Molm et al., 2001), experimental research also has focused almost exclusively on those relations which concern the split of an identical surplus.

Third, theories for exchange networks usually refer to a scenario in which an exchange in one relation tends to prevent transfers in others. Put differently, they often consider exchange networks with substitutable relations only. This focus is narrow because, following Cook et al. (1983), Cook and Emerson (1978) as well as Emerson (1972), one can

\footnotetext{
1 Special issues of journals (cf., Social Networks 14(3-4), 1992 and, at least partly, Rationality and Society 9(1-2), 1997) contain additional articles and controversies.
} 
distinguish between positively and negatively connected exchange relations-a positive connection exists if a resource transfer in one relation tends to promote transfers in others (e.g., communication networks), whereas a negative connection exists if a resource transfer in one relation tends to preclude transfers in others (e.g., dating networks). It makes sense that researchers, while designing experiments, decided to look at positively and negatively connected relations separately. Theory formation, however, was closely associated with experiments on negatively connected systems only. As a consequence, just a few models explicitly allow for positively connected relations as well (e.g., Yamaguchi, 1996). ${ }^{2}$

Fourth, apart from a few exceptions (e.g., Bonacich and Bienenstock, 1995; Friedkin, 1995; Simpson and Willer, 1999), many theories do not systematically predict whether given links to bargaining partners lead to actual deals if, as is often assumed in experiments, actors may complete at most one exchange per round. In such an extreme case of negatively connected networks, actors may have several bargaining partners, but face an exogenously fixed restriction with respect to the acceptable number of exchange partners (e.g., monogamy rule). As a consequence, they may have to select their actual exchange partners from a larger set of potential exchange partners. Since most models neglect the exchange patterns between adjacent positions, many theorists focus on those network structures for which bargaining and exchange relations always coincide ("robust networks").

To be more precise, most exchange theorists analyze specific robust structures-they deal with simple robust networks. In addition to the absence of any deviation between bargaining and exchange structures, such networks consist of exogenously given relations each of which concerns the partitioning of an identical surplus or value between a specific pair of actors on the basis of the same incentives (e.g., all exchange relations are either substitutable or complementary), information (e.g., all actors have complete knowledge about network positions and structure), and restrictions (e.g., nobody may complete more than just one exchange per round).

Furthermore, practically all exchange theories assume that negotiation partners pursue their self-interests. Although interactive and strategic choices characterize negotiations from such a rational actor perspective, however, just a few contributions (e.g., Bienenstock and Bonacich, 1992, 1997) emphasize the relevance of game-theoretic ideas for the analysis of exchange networks. And, the game-theoretic bargaining literature (see, for a review, Muthoo, 1999) has not been adopted in this context.

In what follows, we present and apply a model for the analysis of simple robust exchange networks which draws heavily on this literature. More precisely, the model combines the generalized Nash $(1950,1953)$ bargaining solution from cooperative game theory (cf., Binmore, 1992) with a specific definition of each actor's bargaining power in terms of

\footnotetext{
2 Modifying and extending Coleman's (1973, 1990) competitive equilibrium approach, Yamaguchi (1996) equates negative (positive) connections with closely substitutable (complementary) exchange relations and introduces a flexible continuous parameter for substitutability/complementarity (viz., the elasticity of substitution). Yamaguchi's theory thus embraces situations in which exchange in one relation tends to prevent or promote transfers in others. Its application requires, however, an ad hoc specification of the elasticity of substitution. And, it is limited to the analysis of either substitutable or complementary relations in a given network. Combining basic ideas of his original model with additional assumptions, Yamaguchi (2000) presents a theoretical analysis of structures characterized by the simultaneous presence of both substitutability and complementarity among the multiple exchange relations of a single actor.
} 
relational features and network embeddedness. The new model gives point predictions for bargaining outcomes in those exchange networks studied often in experimental research. Following the presentation of the model in the next section, we describe typical experiments and our data selection criteria. Then, we substantiate the empirical relevance of the model via two applications. In doing so, we follow the practice of exchange theorists (e.g., Burke, 1997; Friedkin, 1995; Yamaguchi, 1996) and rely on published experimental evidence for empirical validation. More precisely, we compare predictions from the new model with available experimental findings and relevant predictions from other popular approaches. And, because of the good fit with experimental results for simple robust networks, we conclude with a brief discussion of possible model extensions for the analysis of complex exchange structures.

\section{Theoretical model}

Consider an exogenously given network with $m$ mutual ties between a finite number of rational actors $(i, j, k=1,2, \ldots, n)$. These symmetric relations limit the matches of potential partners for negotiations and exchanges. Each bargaining session refers, by postulate, to the bilateral distribution of a fixed quantity of a perfectly divisible resource (e.g., money). Exchange appears here, in accordance with sociological approaches (e.g., Bonacich and Friedkin, 1998; Willer, 1999), as an agreement of two rational actors on the division of a fixed surplus. Specifically, we assume that the actors $i$ and $j$ bargain over the partition of a given surplus or value $v$. When $x_{i j}$ represents $i$ 's negotiated share of the value $v$, it holds that $0 \leq x_{i j} \leq v{ }^{3}$ Put differently, $x_{i j}$ denotes $i$ 's negotiated exchange profit in the relation with $j$.

The profit shares $x_{i j}$ and $x_{j i}$ are to be explained in terms of structure. For that purpose, it is postulated that, once $i$ and $j$ negotiate over the partition of $v$, they determine their profit shares as if they would apply the generalized version of the Nash $(1950,1953)$ bargaining solution from cooperative game theory (see, e.g., Binmore, 1987, 1992). That is, they choose the profit shares $x_{i j}$ and $x_{j i}$ as if they would solve the optimization problem

$$
\max x_{i j}^{b_{i}} x_{j i}^{b_{j}} \text { subject to } x_{i j}+x_{j i}=v,
$$

where the positive parameters $b_{i}$ and $b_{j}$ refer to $i$ 's and $j$ 's absolute level of individual bargaining power. As will become clear below, the solution of this optimization problem implies that the split of the given surplus between $i$ and $j$ just reflect the combination of their bargaining powers (i.e., the distribution of "relative bargaining power" determines the negotiated exchange profits).

Apart from its simplicity, there are several arguments in favor of the generalized Nash bargaining solution. First of all, Binmore (1992: 184-188) proves that the solution of the optimization problem specified in Eq. (1) is the only bargaining solution which satisfies the following three axioms: (A) the bargaining outcome does not depend on how the negotiation

\footnotetext{
${ }^{3}$ If the actors perpetually disagree, they do not get a proportion of the surplus. That is, the payoff associated with disagreement is 0 for both network partners.
} 
partners' utility scales are calibrated; (B) the bargaining outcome is individually rational and Pareto-efficient; (C) the actors' choice is independent of the availability or unavailability of irrelevant alternatives (i.e., if the bargaining partners sometimes agree on a specific outcome when another outcome is feasible, then they will never agree on the latter when the former is feasible). Therefore, the generalized Nash bargaining solution is compatible with weak and plausible assumptions on utilities, choices, and outcomes.

Second, the generalized bargaining solution does not require the assumption of perfectly rational actors. Young (1993, 2001: Chapter 8) proves that the generalized Nash bargaining solution is "stochastically stable". Accordingly, the high-rational solution from game theory also has a representation in a low-rational environment through a process of learning-while no player may be perfectly rational, repeated exposure to the same situation will induce a learning process such that there is a convergence to the generalized Nash bargaining solution. It thus can be expected that, due to the process of learning, experimental subjects will split the cake at least in later rounds as if they would apply the generalized Nash bargaining solution.

Third, the solution of the optimization problem specified in Eq. (1) corresponds, for specific conditions, to the limiting equilibrium outcome of Rubinstein's (1982) Alternating Offers Game. The latter is a non-cooperative game between two rational egoists who alternate in proposing how to divide a pie with one time period elapsing between each offer. The generalized Nash bargaining solution coincides with the subgame-perfect Nash equilibrium outcome of Rubinstein's game if the focus is on the limiting scenario in which the amount of time between proposals vanishes (cf., Binmore, 1985, 1998; Muthoo, 1999; Osborne and Rubinstein, 1990). From this perspective, the generalized Nash bargaining solution is an appropriate cooperative solution concept because, in contrast to other cooperative solution concepts (e.g., core, kernel), it can be derived from a strategic analysis in the sense of non-cooperative game theory. That is, selfish rational actors who play the non-cooperative Alternating Offers Game in which there are only negligible delays between proposals will divide the cake as if they would apply the generalized Nash bargaining solution.

This insight is particularly important if one follows Nash $(1950,1951,1953)$ in regarding non-cooperative games as more fundamental than cooperative games. And, it is not restricted to the strict logic of the Alternating Offers Game. This becomes clear when the gametheoretic analysis of an alternative non-cooperative bargaining model by Perry and Reny (1993) is taken into account; Perry and Reny show that if actors can make offers whenever they want (i.e., when all sequences of offers are possible but actors must wait a fixed, though small, amount of time before making another offer), all subgame-perfect equilibria of such a game are Rubinstein-like. As a consequence, the limiting equilibrium solution of the Alternating Offers Game-and therefore the generalized Nash bargaining solutionallows exchange predictions at the dyadic level even when the bargaining procedure does not require a strict alternation between offers and counteroffers until agreement is reached, but ensures that actors can make offers whenever they want.

These arguments justify the use of the generalized Nash bargaining solution in a model for exchange networks. The concrete application of the generalized Nash bargaining solution requires a numerical specification of each actor's bargaining power. It is precisely here where the basic idea of sociological theories for exchange networks comes in-we assume that, once the network relations have been classified as negative or positive connections, 
each actor's bargaining power results from his structural position in the network under consideration. Therefore, our model essentially combines the generalized version of the Nash bargaining solution with a specific definition of each actor's bargaining power in terms of relational features and structural embeddedness. Before we go into the details of modeling, it is useful to list our basic premises, each of which is then discussed in more detail:

1. Depending on their structural positions in the exogenous bargaining network, actors differ in terms of their "network control" (i.e., the extent to which an actor controls the relations to him by his relations to others).

2. Depending on the type of exchange network an actor faces (i.e., either substitutable or complementary relations), his network control positively or negatively affects his individual bargaining power.

3. Depending on the individual bargaining powers, the generalized Nash bargaining solution determines the distributions of relative bargaining power and exchange profit in the exchange network under consideration.

In accordance with this chain of postulates, we now successively present the assumptions and implications of our approach. Starting from a given negotiation structure, the actors' network control is to be determined first.

\subsection{Bargaining structure and network control}

Let the $n \times n$ adjacency matrix $\mathbf{A}$ with main diagonal elements $a_{i i}=0$ for all $i$ and off-diagonal elements $a_{i j} \geq 0$ represent the exogenously given and symmetric bargaining relations. For simplicity, $a_{i j}=a_{j i}$ is a binary measure for the absence or presence of a mutual tie between the actors $i$ and $j$ (i.e., $a_{i j}=a_{j i}$ is coded as 0 or 1 for all $i \neq j$ ).

Without loss of generality, we can standardize $\mathbf{A}$. Let $\mathbf{R}$ be the $n \times n$ matrix of standardized actor relations such that $r_{i i}=0$ for all $i, r_{i j}:=a_{i j} / \sum_{k=1}^{n} a_{k j} \geq 0$ for all $i, j$, and $\sum_{k=1}^{n} r_{k j}=1$ for all $j$. That is, $\mathbf{R}$ is the column-stochastic matrix derived from the adjacencies. Its off-diagonal element $r_{i j}$ measures $i$ 's fraction of the systemwide relations to $j$. In other words, $r_{i j}$ represents $i$ 's degree of "control" over the relations to $j$ in the system. Specifically, it holds $0 \leq r_{i j} \leq 1$, where $r_{i j}=0$ indicates that $i$ has no control over $j$ (i.e., absence of a tie between $i$ and $j$ ) and $r_{i j}=1$ reflects that $i$ has complete control over $j$ (i.e., $i$ is $j$ 's only bargaining partner).

The $i$ th row of the matrix $\mathbf{R}$ informs about $i$ 's control over each other actor in the system, whereas the $i$ th column of $\mathbf{R}$ informs about each other's control over $i$. Adding up the relevant pairwise elements of $\mathbf{R}$ defines the "network control" of actor $i$ :

$$
c_{i}:=\sum_{k=1}^{n} r_{i k} r_{k i} \quad \text { for all } i .
$$

Put verbally, $c_{i}$ is the degree to which $i$ controls the relations to him by his relations to others. For example, $c_{i}=3 / 4$ means that actor $i$ controls, via his relations to others, three-fourth of their relations to him. The control fraction $c_{i}$ thus may be interpreted as $i$ 's "structural 
autonomy" as well. ${ }^{4}$ And, its calculation is straightforward. A closer look at Eq. (2) shows that $c_{i}$ may be alternatively expressed as the mean of the $i$ th row in the matrix $\mathbf{R}$. In other words, $i$ 's network control is the mean of $i$ 's control over the systemwide relations to his partners:

$$
c_{i}=\frac{1}{n_{i}} \sum_{k=1}^{n} r_{i k} \text { for all } i,
$$

where $n_{i}$ denotes the number of $i$ 's bargaining partners. Since the number of positive elements in the $i$ th row in $\mathbf{R}$ is always $n_{i}$, the relevant control distribution can be practically read off from the standardized actor relations (see, for illustrations, Fig. 1 below).

The concept of network control requires only weak assumptions about the structural information of network members. This becomes more obvious if $c_{i}$ is expressed in yet another way. Let $S_{i}$ denote the set of the $n_{i}$ bargaining partners of actor $i$. It is possible to express $c_{i}$ as

$$
c_{i}=\frac{1}{n_{i}} \sum_{k \in S_{i}} \frac{1}{n_{k}}=\frac{1}{\left(n_{i} / \sum_{k \in S_{i}}\left(1 / n_{k}\right)\right)} \quad \text { for all } i .
$$

Stated differently, $i$ 's network control $c_{i}$ reflects how many negotiation partners actor $i$ and his partners have. Hence, information about the number of $i$ 's bargaining partners and the numbers of their partners allows the calculation of $i$ 's network control. ${ }^{5}$

A closer inspection of the far right-hand side of Eq. (4) shows, moreover, that the concept of network control is compatible with a rational actor perspective $-c_{i}$ is simply the reciprocal of the estimate a rational actor $i$ will have for the mean number of partners of his partners in a given network. ${ }^{6}$ For example, $c_{i}=3 / 4$ expresses that the average number of bargaining partners of $i$ 's partners is $4 / 3=1.333$. When the assumption is made that $i$ knows his network control, it is postulated, in effect, that $i$ takes account of the mean number of partners of his partners.

The degrees of network control are, by postulate, essential determinants of the individual bargaining powers. That is, actor $i$ 's network control $c_{i}$ affects $b_{i}$, $i$ 's level of bargaining power. The direction of the relationship between network control $c_{i}$ and bargaining power $b_{i}$ depends, however, on the categorization of the respective exchange networks.

\footnotetext{
${ }^{4}$ The definition of network control (cf., Eq. (2)) shows that the $c_{i}$ 's are the positive main diagonal elements of the $n \times n$ matrix $\mathbf{C}:=\mathbf{R R}$. That is, $c_{i}=c_{i i}>0$ for all $i$. Like $\mathbf{R}, \mathbf{C}$ is a column-stochastic matrix. That is, $0<c_{i} \leq 1$ and $1-c_{i}=\sum_{k \neq i} c_{k i} \geq 0$ for all $i$. Since the upper bound of $c_{i}$ is 1 , its complement $1-c_{i}$ measures $i$ 's "structural dependence" (i.e., the degree to which the other system members affect, via their relations to one another, the relations to actor $i$ ).

5 Consequently, we do not have to assume that every actor has complete information about the overall shape of the network structure. It suffices to postulate that everyone has complete information about his 'immediate vicinity'.

${ }^{6}$ Feld (1991) explains why friends always seem to have more friends than oneself. For the scenario in which this 'class size paradox' is fully understood, he also derives the appropriate estimate for the mean number of friends of an individual's friends. The latter corresponds with the denominator of the far right-hand side of Eq. (4).
} 


\subsection{Network categorization and bargaining power}

We focus on such network structures in which everybody knows, apart from his network control, that each link concerns the bilateral split of an identical surplus or value. It is also assumed that everybody knows the exchange restrictions (e.g., completion of just one exchange per round) and the type of network connections all system members face. Put differently, it is common knowledge that all given relations are either substitutable (negatively connected) or complementary (positively connected). ${ }^{7}$

Given these postulates, we now can specify how network control affects bargaining power. Imagine first a system with negatively connected relations. Such a network has two essential features: $i$ 's bargaining relations are substitutable and compete with the relations of $i$ 's partners to others. Both features suggest that $i$ 's bargaining power rises with his network control-by definition, more control means that $i$ depends less on his current negotiation partner for exchange and that $i$ 's bargaining partners tend to have fewer alternatives. For the case of negatively connected relations, it thus can be assumed that $i$ 's bargaining power $b_{i}$ rises with $i$ 's network control $c_{i}$.

It is reasonable to postulate just the contrary for the opposite scenario of positively connected relations. In a setting with positive connections, relations with different partners ensure the resource flow through the system. And, if an actor's network control or structural autonomy is lower, the others have a stronger effect, via their links to one another, on the relations to him. Put differently, if $i$ 's network control is smaller, he possesses, by definition, a higher structural dependence and this creates additional opportunities in a setting with positive connections. For example, due to the others' transactions, a less autonomous actor may serve as a broker or crucially affect the resource flow through the system. For the case of positively connected relations, it thus can be assumed that $i$ 's bargaining power $b_{i}$ increases if $i$ 's network control $c_{i}$ decreases.

To formalize these ideas, we follow Binmore (1985, p. 273) who defines individual bargaining power as the negative reciprocal of a logarithmic expression. It is assumed that

$$
b_{i}:= \begin{cases}-1 / \ln \left(w c_{i}\right) & \text { if } i \text { faces a negatively connected exchange network } \\ -1 / \ln \left(1-w c_{i}\right) & \text { if } i \text { faces a positively connected exchange network }\end{cases}
$$

where we use the shorthand

$$
w:=\frac{m+n}{1+m+n} .
$$

The latter is a network-specific fraction which rises with the number of mutual ties in the network, $m$, and the number of network members, $n$. In Eq. (5), the weight $w$ scales the degrees of network control or structural autonomy such that $b_{i}$ is always a positive number. ${ }^{8}$

\footnotetext{
${ }^{7}$ In accordance with most published work in the field, we exclude mixtures of positive and negative connections. Since our focus is on simple networks, we restrict our attention to exchange structures with either negative or positive connections only.

8 There are three reasons for Eq. (6), the specific definition of $w$. First, admissible transformations of network control are those which just change the unit of scale. The weight $w$ clearly fulfills this requirement. Second, any bargaining network may be characterized by the number of mutual ties, $m$, and the number of system actors, $n$.
} 
Starting from the distribution of network control, each actor's bargaining power results from combining Eqs. (5) and (6) for the network under consideration. We now can specify the negotiation outcomes associated with the two types of exchange networks.

\subsection{Exchange outcomes and network types}

As already discussed, we postulate that $i$ and $j$ determine their profit shares in negotiations over the partitioning of the given value $v$ as if they would solve the optimization problem expressed in Eq. (1). The maximization of the equivalent welfare function $x_{i j}^{b_{i}}\left(v-x_{i j}\right)^{b_{j}}$ implies that $i$ can obtain the exchange profit

$$
x_{i j}=\left(\frac{b_{i}}{b_{i}+b_{j}}\right) v=p_{i j} v \quad \text { for } i \neq j,
$$

where $p_{i j}:=b_{i} /\left(b_{i}+b_{j}\right)$ defines $i$ 's relative bargaining power in the relation with $j$. And, since $p_{j i}=1-p_{i j}$ holds by definition, $i$ 's partner $j$ will receive $x_{j i}=\left(1-p_{i j}\right) v=p_{j i} v$.

Accordingly, the optimal partition of the given surplus depends on the combination of $b_{i}$ and $b_{j}$. Put differently, the bargaining power of just one partner is irrelevant for the negotiation outcome-it is the relative bargaining power (i.e., $p_{i j}$ or $p_{j i}=1-p_{i j}$ ) which matters for the profit split. Since $x_{i j}=p_{i j} v$ and $x_{j i}=\left(1-p_{i j}\right) v$, a comparison of actor $i$ 's profit share with that of his bargaining partner $j$ yields the following chain of equivalent conclusions:

$$
x_{i j} \gtreqless x_{j i} \Longleftrightarrow x_{i j} \gtreqless \frac{1}{2} v \Longleftrightarrow p_{i j} \gtreqless \frac{1}{2} \Longleftrightarrow b_{i} \gtreqless b_{j} \quad \text { for } i \neq j .
$$

Put verbally, a symmetric distribution of bargaining powers $\left(b_{i}=b_{j}\right.$ or $\left.p_{i j}=1 / 2=p_{j i}\right)$ always yields an equal split of the pie $\left(x_{i j}=v / 2=x_{j i}\right)$. There will be an unequal profit division, however, when the power of the two negotiation partners differs. Specifically, $i$ 's exchange profit $x_{i j}$ dominates $j$ 's exchange profit $x_{j i}$ such that $i$ gets more than half of the pie if and only if $p_{i j}$ exceeds $p_{j i}$. Because of $p_{i j}+p_{j i}=1$, the latter is satisfied if and only if $i$ 's relative bargaining power in the relation with $j$ exceeds $1 / 2$. And, this is equivalent to the condition that $i$ 's absolute bargaining power $b_{i}$ exceeds $j$ 's absolute bargaining power $b_{j}$.

The actors' bargaining powers depend, by postulate, on their structural embeddedness and relational features. As a consequence, the model implications reflect these determinants. Substituting Eq. (5) into Eq. (7) gives specific conclusions about the exchange profits in the different network types:

\footnotetext{
It thus is reasonable to define the scaling factor $w$ in terms of these system parameters. Third, weighting should preserve the essential role of network control in our approach. The weight $w$ is a systemwide constant which, at most, moderately changes the original values of network control-because of $m \geq 1$ and $n \geq 2$, it holds that $3 / 4 \leq w<1$.
} 
Negatively connected network: If the actors $i$ and $j$ negotiate in a negatively connected network, then $i$ 's exchange profit in the match with $j$ is

$$
\begin{aligned}
x_{i j}=p_{i j} v=\frac{b_{i}}{b_{i}+b_{j}} v & =\left(\frac{\left[-1 / \ln \left(w c_{i}\right)\right]}{\left[-1 / \ln \left(w c_{i}\right)\right]+\left[-1 / \ln \left(w c_{j}\right)\right]}\right) v \\
& =\left(\frac{\ln \left(w c_{j}\right)}{\ln \left(w c_{i}\right)+\ln \left(w c_{j}\right)}\right) v \text { for } i \neq j .
\end{aligned}
$$

Hence, $i$ 's relative bargaining power and exchange profit in a substitutable relation with $j$ rise, everything else being constant, when either $i$ 's network control $c_{i}$ increases or $j$ 's network control $c_{j}$ decreases. ${ }^{9}$

Positively connected network: If the actors $i$ and $j$ negotiate in a positively connected network, then $i$ 's exchange profit in the match with $j$ is

$$
\begin{aligned}
x_{i j}=p_{i j} v=\frac{b_{i}}{b_{i}+b_{j}} v & =\left(\frac{\left[-1 / \ln \left(1-w c_{i}\right)\right]}{\left[-1 / \ln \left(1-w c_{i}\right)\right]+\left[-1 / \ln \left(1-w c_{j}\right)\right]}\right) v \\
& =\left(\frac{\ln \left(1-w c_{j}\right)}{\ln \left(1-w c_{i}\right)+\ln \left(1-w c_{j}\right)}\right) v \quad \text { for } i \neq j .
\end{aligned}
$$

Consequently, actor $i$ 's relative bargaining power and negotiated profit in a complementary relation with $j$ increase, everything else being constant, if either $i$ 's network control $c_{i}$ falls or $j$ 's network control $c_{j}$ rises.

Since $w:=(m+n) /(1+m+n)$ and $c_{i}:=\sum_{k} r_{i k} r_{k i}$ hold by definition and $r_{i j}$ measures $i$ 's fraction of the systemwide relations to $j$, we thus may uniquely predict the distributions of relative bargaining power and negotiated profit for any simple exchange structure with either substitutable or complementary relations.

Concrete analyses of such network structures illustrate, as will become clear below, the straightforward application of our approach. To compare such theoretical predictions with empirical observations, we first need to describe and select relevant experimental studies.

\section{Experiments and data selection}

There are various experimental results with regard to profit and power distributions in simple exchange networks (e.g., Bienenstock and Bonacich, 1993; Lovaglia et al., 1995; Skvoretz and Fararo, 1992; Skvoretz and Willer, 1993; Yamagishi et al., 1988). Since many experiments have been conducted, several exchange theorists (e.g., Burke, 1997; Friedkin, 1995; Yamaguchi, 1996) substantiate the empirical relevance of new theoretical ideas by referring to an appropriate subset of the published findings. We also

\footnotetext{
9 These conclusions reflect that $\partial p_{i j} / \partial c_{i}>0, \partial p_{i j} / \partial c_{j}<0$ and $\partial x_{i j} / \partial c_{i}>0$ as well as $\partial x_{i j} / \partial c_{j}<0$. The signs of these partial derivatives inform about the reaction of $i$ 's relative bargaining power $p_{i j}$ and $i$ 's profit share $x_{i j}$ in the match with $j$ when exogenous structural changes affect either $i$ 's network control $c_{i}$ or $j$ 's network control $c_{j}$, but preserve the valued relation between $i$ and $j$.
} 
adopt this strategy of empirical validation. To specify the relevant data selection criteria, it is reasonable to briefly describe features of experimental studies on exchange networks.

\subsection{Experimental work}

Starting point of an exchange network experiment is a specific bargaining structure which limits matches between potential exchange partners. Experimenters are interested in the effects the structural embeddedness has on profit splits between adjacent nodes. The presentation of experimental findings therefore refers to the types of structural positions (A, B, C, D, and E) the different actors have. Individuals located at structurally equivalent positions are normally distinguished by numeric subscripts (e.g., $\mathrm{A}_{1}, \mathrm{~A}_{2}$ ).

Fig. 1 depicts negotiation structures most of which are popular in laboratory experiments. Nearly all of those experiments focus on networks with equally valued relations (i.e., each bilateral bargaining session concerns the division of an identical surplus). To prepare the application of our model to such structures, Fig. 1 also informs about the relevant columnstochastic matrices $\mathbf{R}$ with elements $r_{i j}$ and the associated control vectors $\mathbf{c}$ with entries $c_{i}:=\sum_{k} r_{i k} r_{k i}$ for all $i$.

The design of experiments on exchange networks has common features (see, e.g., Skvoretz and Willer, 1991). All experiments consist of several rounds of negotiation and exchange, while the relational structure is kept constant. Bargaining sessions involve adjacent network positions only, where usually a cake of identical size (normally 24 "profit points") is to be split in any bilateral match. After a series of offers and counteroffers, negotiations stop when an agreement is reached. Partly due to a computerized setting, proposals can be made within seconds and bargaining sessions do not last long (viz., agreement in less than a few minutes). Most experiments concern negatively connected networks. The experimental design often restricts the number of exchanges per connection and round-empirical research usually refers to those negatively connected settings in which every actor is subject to the same exchange restriction (e.g., one-exchange rule).

Subjects are usually undergraduates who participate for pay (monetary compensation according to bargaining success). They receive general information about the purpose and the number of rounds of the experiment. Training and practice rounds serve to ensure their understanding of the bargaining situation. And, there is no misdirection. Subjects normally possess complete information about the bargaining rules, the earnings of their partners, the shape of the negotiation structure, and their own positions within the network. ${ }^{10}$

To eliminate possible effects of interindividual heterogeneity, researchers apply different procedures. Some authors (e.g., Bonacich and Friedkin, 1998) randomly assign subjects to fixed network positions and prevent face to face encounters (i.e., subjects sit in separate rooms and interact through computer terminals). Others (e.g., Lovaglia et al., 1995) ensure

\footnotetext{
$\overline{10}$ In some experimental studies, however, the subjects did not know the overall shape of network structures, their own network positions, or the other players' earnings (e.g., Bonacich and Friedkin, 1998; Thye et al., 1997; Yamagishi et al., 1988).
} 
TRIANGLE

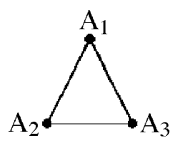

3 -LiNE

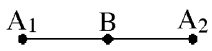

4 - LINE
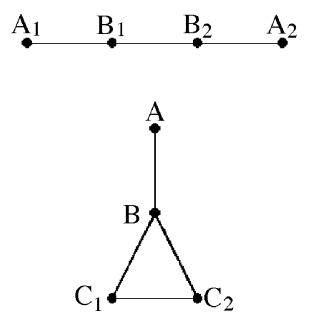

KITE

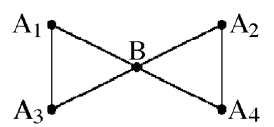

3 - BRANCH

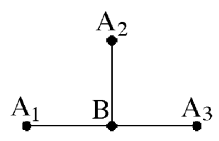

5 - LINE
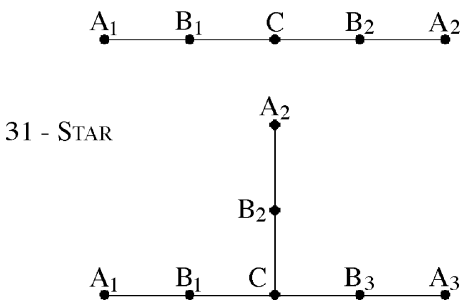

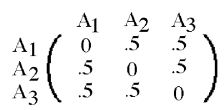$$
\begin{aligned}
& \mathrm{A}_{1} \\
& \mathrm{~A}_{2} \\
& \mathrm{~A}_{3}
\end{aligned}\left(\begin{array}{l}
.5000 \\
.5000 \\
.5000
\end{array}\right)
$$

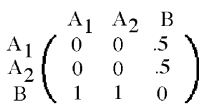$$
\mathrm{A}_{2} \mathrm{~A}_{1}\left(\begin{array}{l}
.5000 \\
.5000 \\
1.000
\end{array}\right)
$$$$
\mathrm{A}_{1}\left(\begin{array}{cccc}
\mathrm{A}_{1} & \mathrm{~A}_{2} & \mathrm{~B}_{1} & \mathrm{~B}_{2} \\
\mathrm{~A}_{2} & 0 & .5 & 0 \\
\mathrm{~B}_{1} & 0 & 0 & .5 \\
\mathrm{~B}_{2} & 0 & 0 & .5 \\
0 & 1 & .5 & 0
\end{array}\right)
$$$$
\begin{aligned}
& \mathrm{A}_{1} \\
& \mathrm{~A}_{2} \\
& \mathrm{~B}_{1} \\
& \mathrm{~B}_{2}
\end{aligned}\left(\begin{array}{l}
.5000 \\
.5000 \\
.7500 \\
.7500
\end{array}\right)
$$

STEM

$\mathrm{A}$
$\mathrm{B}$
$\mathrm{C}_{1}$
$\mathrm{C}_{2}$$\left(\begin{array}{cccc}\mathrm{A} & \mathrm{B} & \mathrm{C}_{1} & \mathrm{C}_{2} \\ 0 & .33 & 0 & 0 \\ 1 & 0 & .5 & .5 \\ 0 & .33 & 0 & .5 \\ 0 & .33 & .5 & 0\end{array}\right)$

$$
\begin{gathered}
\mathrm{A} \\
\mathrm{B} \\
\mathrm{C}_{1} \\
\mathrm{C}_{2}
\end{gathered}\left(\begin{array}{l}
.3333 \\
.6667 \\
.4167 \\
.4167
\end{array}\right)
$$

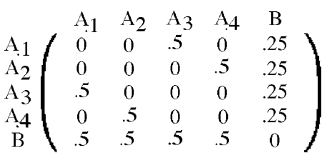$$
\begin{gathered}
\mathrm{A}_{1} \\
\mathrm{~A}_{2} \\
\mathrm{~A}_{3} \\
\mathrm{~A}_{4} \\
\mathrm{~B}
\end{gathered}\left(\begin{array}{l}
.3750 \\
.3750 \\
.3750 \\
.3750 \\
.5000
\end{array}\right)
$$$$
\mathrm{A}_{1} \mathrm{~A}_{2}\left(\begin{array}{cccc}
\mathrm{A}_{1} & \mathrm{~A}_{2} & \mathrm{~A}_{3} & \mathrm{~B} \\
0 & 0 & 0 & .33 \\
0 & 0 & 0 & .33 \\
0 & 0 & 0 & .33 \\
1 & 1 & 1 & 0
\end{array}\right)
$$$$
\begin{gathered}
\mathrm{A}_{1} \\
\mathrm{~A}_{2} \\
\mathrm{~A}_{3}
\end{gathered}\left(\begin{array}{c}
.3333 \\
.3333 \\
.3333 \\
1.000
\end{array}\right)
$$

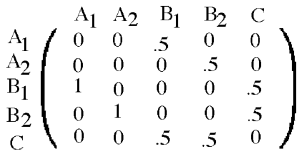

$\mathrm{A}_{1}$
$\mathrm{~A}_{2}$
$\mathrm{~B}_{1}$
$\mathrm{~B}_{2}$
$\mathrm{C}^{2}$$\left(\begin{array}{l}.5000 \\ .5000 \\ .7500 \\ .7500 \\ .5000\end{array}\right)$

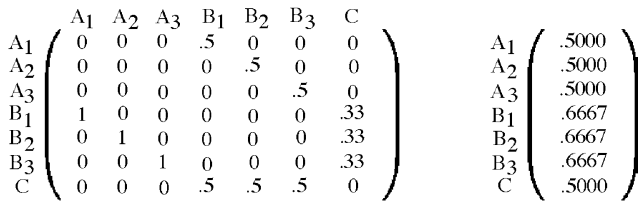

Fig. 1. Network structures, relational matrices $\mathbf{R}$, and control vectors $\mathbf{c}$.

an impersonal experimental setting as well, but rotate subjects through all network positions during the experiment. In addition, both procedures should help inhibit, partly in combination with other aspects of the experimental design (e.g., lack of information on other players' earnings), possible effects of individual preferences for equality in earnings over 
the entire experiment. It is not clear, however, whether these precautions are fully effective or, if not, which procedure is more appropriate. ${ }^{11}$

Nevertheless, experimental results are often interpreted as effects the given network structure has on exchange patterns and/or profit divisions between adjacent positions. As a matter of fact, however, they are averages of what happened over a limited number of negotiated exchanges. And, results on exchange profits are routinely represented by the means of profit points the advantaged positions in given matches could realize over several rounds of the experiment. Occasionally, they are reported as systemwide fractions of power associated with structural positions (i.e., in our terminology, the relative bargaining powers of position holders are standardized over all matches such that they add up to unity over all network members). Before we confront our theoretical predictions with such empirical evidence, a few words about our choice of data may be helpful.

\subsection{Selection of experiments}

Several aspects characterize our choice of empirical data. First, in accordance with the domain of our model, we focus on those experiments which concern identically valued relations.

Second, we restrict our attention to those experimental studies in which subjects possess complete information about the bargaining rules, the earnings of their partners, the shape of the negotiation structure, and their own positions within the network. This decision simply reflects the assumptions of our theory-actors have to know at least their own relations and those of their partners as well as the numbers of mutual ties and actors in the network.

Third, apart from one exception, we compare theoretical predictions with experimental results on negatively connected structures. This reflects that Yamagishi et al. (1988) is the only experimental study of a positively connected setting. In addition to empirical work on negative connections (e.g., Cook et al., 1983; Markovsky et al., 1988), we therefore refer to the latter in our comparison with Yamaguchi's (1996) theory, the only other model for negatively and positively connected relations.

Fourth, because of the relatively large number of experiments on negatively connected structures, we select a subset of those studies. This subset is characterized by a similar design - our focus will be on experiments in which (I) each position holder faces the same exchange restriction (e.g., one-exchange rule), and (II) subjects are rotated through all network positions. The selection criterion (I) reflects that the bulk of published experiments is subject to this restriction. The selection criterion (II) reflects a methodological point. As mentioned, experimenters try to inhibit possible effects of subjects' desire for equality in earnings via two distinct procedures (random assignment to fixed positions vs. rotation of subjects through all structural positions)—-the more appropriate procedure is not known

\footnotetext{
11 This conclusion reflects statements of experimenters who apply the different procedures. To rationalize specific empirical results, Lovaglia et al. (1995) refer to the potential problem of subjects' preferences for equity in experimental research. Bonacich and Friedkin (1998) also mention that their results may have been affected by such preferences.
} 
yet, however. To avoid biases as far as possible, we therefore fix the procedure and mainly refer to such studies on negatively connected structures in which subjects were rotated through network positions. ${ }^{12}$ While this selection criterion may seem restrictive, there are enough published data for a systematic comparison of predictions from our network control bargaining (hereafter, NCB) model and other theories.

\section{Applications}

\subsection{Dyadic profit splits}

Using experimental results obtained by Skvoretz and Willer (1993) as reference point, Table 1 compares NCB-predictions for dyadic exchange outcomes in popular networks (4Line, Stem, KITE, 3-BrAnCH, see Fig. 1) with those of alternative approaches. The latter are Lovaglia et al.'s (1995) GPI-RD, Yamaguchi's (1996) power model (Y), Skvoretz and Willer's (1993) exchange resistance theory (ER), Friedkin's (1986, 1992) expected value theory (EV), Yamagishi and Cook's (1992) equi-dependence theory (ED), and Burke's (1997) identity simulation model (IS). ${ }^{13}$ The observations listed in Table 1 refer to estimated means of profit points of structural position $\mathrm{B}$, where 24 profit points per match had to be divided.

The associated NCB-predictions follow, for the given size of the cake of 24 , from inserting the actors' degrees of structural autonomy (cf., Fig. 1) and the network-specific weight into Eq. (9), the equation for dyadic profit shares in a negatively connected relation. To illustrate the procedure, let us take a look at the 4-LinE structure and compute the relevant profit points. Fig. 1 informs about the structural autonomy levels or degrees of network control: $c_{\mathrm{A}_{1}}=0.5=c_{\mathrm{A}_{2}}$ and $c_{\mathrm{B}_{1}}=0.75=c_{\mathrm{B}_{2}}$. It also gives the number of mutual ties $(m=3)$ and the number of system actors $(n=4)$ such that $w=(m+n) /(1+m+n)=0.875$. Substituting into Eq. (9) yields, when numeric subscripts are dropped for notational convenience, the profit point prediction for $\mathrm{B}$ in the match with A:

$$
x_{\mathrm{BA}}=p_{\mathrm{BA}} \times 24=\left(\frac{\ln (0.875 \times 0.5)}{\ln (0.875 \times 0.75)+\ln (0.875 \times 0.5)}\right) \times 24=15.9
$$

such that $x_{\mathrm{AB}}=\left(1-p_{\mathrm{BA}}\right) \times 24=24-15.9=8.1$ gives the profit points for $\mathrm{A}$ in the relation with B. In addition to such NCB-predictions, Table 1 contains profit point predictions from other models. To compare the empirical performance of the theories, we use two "goodness-of-fit" measures, viz., the "Absolute Deviation" (AD) and the "Mean Deviation" (MD). Whereas AD is the average absolute difference between

\footnotetext{
12 The only exception is Cook et al.'s (1983) study. In their experimental setting, subjects were neither rotated nor informed about their partners' earnings. Following Yamaguchi (1996), Markovsky et al. (1997), we include the Cook et al. data in our comparison with Yamaguchi's theory.

13 We selected those approaches because, in contrast to other published theories (e.g., Bienenstock and Bonacich, 1992), they offer profit point predictions for all networks under study.
} 
Table 1

Dyadic exchange profits in negatively connected networks

\begin{tabular}{|c|c|c|c|c|c|c|c|c|c|}
\hline \multirow[t]{2}{*}{ Network } & \multirow[t]{2}{*}{ Match } & \multicolumn{7}{|c|}{ Theoretical predictions ${ }^{\mathrm{a}}$} & \multirow[t]{2}{*}{ Observed $^{b}$} \\
\hline & & NCB & GPI-RD & $\mathrm{Y}$ & ER & EV & ED & IS & \\
\hline 4-Line & $\mathrm{B}: \mathrm{A}$ & 15.9 & $14.5^{\dagger}$ & $13.3^{\dagger}$ & 16.0 & 21.1 & 16.0 & $13.8^{\dagger}$ & $14.1(0.40)$ \\
\hline \multirow[t]{2}{*}{ STEM } & B:A & $16.8^{\dagger}$ & $15.6^{\dagger}$ & $14.4^{\dagger}$ & 18.3 & 22.0 & 18.0 & $15.6^{\dagger}$ & $15.3(0.82)$ \\
\hline & $\mathrm{B}: \mathrm{C}$ & $15.7^{\dagger}$ & $13.7^{\dagger}$ & $13.2^{\dagger}$ & $15.2^{\dagger}$ & $19.5^{\dagger}$ & $14.4^{\dagger}$ & $12.9^{\dagger}$ & $16.5(2.64)$ \\
\hline KITE & B:A & $13.9^{\dagger}$ & $13.7^{\dagger}$ & $12.8^{\dagger}$ & $12.5^{\dagger}$ & 12.0 & 12.0 & 12.1 & $14.1(0.77)$ \\
\hline 3-BRANCH & B:A & $21.7^{\dagger}$ & $23.0^{\mathrm{c}}$ & 18.0 & $21.2^{\dagger}$ & $22.0^{\dagger}$ & 24.0 & $21.9^{\dagger}$ & $21.6(0.49)$ \\
\hline $\mathrm{AD}^{\mathrm{d}}$ & & 0.88 & 1.06 & 1.98 & 1.64 & 3.84 & 2.24 & 1.30 & \\
\hline $\mathrm{MD}^{\mathrm{d}}$ & & 0.50 & 0.64 & 1.04 & 0.83 & 2.07 & 1.01 & 0.83 & \\
\hline
\end{tabular}

Notes: Experiments took place under an overall one-exchange rule, where 24 profit points per match had to be divided. Predictions and observations are for profit points of structural position B. Profit points for positions A and $\mathrm{C}$ in the match with $\mathrm{B}$ result from (24- profit of B), respectively. NCB = Network control bargaining model; GPI-RD = graph-theoretic power index with resistance and degree (Lovaglia et al., 1995); Y = Yamaguchi's (1996) power model, predictions based on the parameter choice $s=8$ (elasticity of substitution); ER = exchange resistance theory (Skvoretz and Willer, 1993); EV = expected value theory (Friedkin, 1986, 1992); ED = equi-dependence theory (Yamagishi and Cook, 1992); IS = identity simulation model (Burke, 1997).

a Profit predictions, except for GPI-RD, Y, and IS, are taken from Skvoretz and Willer (1993, Table 2); predictions for GPI-RD, Y, and IS are taken from Lovaglia et al. (1995, Table 1), Yamaguchi (1996, Table 3), and Burke (1997, Table 1), respectively.

b Experimental results with standard errors in brackets, as reported by Skvoretz and Willer (1993, Table 2).

c Own calculation, based on Lovaglia et al. (1995).

d $\mathrm{AD}=$ absolute deviation (the sum of absolute distances between observed and predicted profit points relative to number of comparisons); $\mathrm{MD}=$ mean deviation (the Euclidean distance between observed and predicted profit points relative to number of comparisons).

$\dagger$ Daggers indicate that predicted values fall within the $95 \%$ confidence interval of the observed values. Put differently, these predictions fit the observations at the $p<0.05$ significance level (two-tailed tests).

observed and predicted profit points over all matches under consideration, MD is the Euclidean distance between observed and predicted profit points relative to the number of comparisons. $^{14}$

According to the MD and $\mathrm{AD}$ values in Table 1, all theories make acceptable profit point predictions. Nevertheless, they differ in terms of predictive accuracy. In particular, Friedkin's $(1986,1992)$ expected value theory (EV) seems, at first sight, to be an outlier. A closer look reveals, however, that EV predicts poorly with respect to just two matches (viz., the 4-LINE and the B:A relation in the STEM network). These relations also turn out to be problematic for Skvoretz and Willer's (1993) exchange resistance theory (ER) as well as Yamagishi and Cook's (1992) equi-dependence theory (ED). While Burke's (1997) identity

\footnotetext{
${ }^{14}$ While the calculation of AD is straightforward, an example for the computation of MD may be helpful. To obtain the value of MD for the NCB model (see, Table 1), we determine the sum of squared deviations between observations and predictions: $(14.1-15.9)^{2}+(15.3-16.8)^{2}+(16.5-15.7)^{2}+(14.1-13.9)^{2}+(21.6-21.7)^{2}=$ 6.18. Taking the square root and dividing the result by the number of comparisons (i.e., $\sqrt{6.18} / 5$ ) gives the reported MD of 0.50 .
} 
simulation model (IS), Lovaglia et al.'s (1995) GPI-RD, and Yamaguchi's (1996) power model (Y) offer much better predictions for those links, they do not closely fit the empirical results for others. ${ }^{15}$ And, even though the NCB model has the lowest AD and MD, it is also not completely in line with the experimental evidence. This can be seen from the more standard test of fit reported in Table 1 as well. Following Skvoretz and Willer (1993) and Yamaguchi (1996), it is asked there whether predictions fall within the 95\% confidence intervals of the empirically observed means. According to this test, the NCB-prediction for the 4-LINE structure does not fit the experimental data. The other NCB-predictions correspond with the evidence, however.

This is important for a specific reason. The empirical observations in Table 1 indicate that negatively connected networks with equally valued relations and structurally distinct positions may considerably differ in terms of profit divisions. Compare, for example, the mean profit points obtained by position B in matches with actors at position $\mathrm{A}$ in the 3-BRANCH and KiTE networks: B gets, on average, 21.6 profit points (i.e., $90 \%$ of the available resources) in the 3-BRANCH network, but 14.1 profit points (i.e., $59 \%$ of the available resources) in the KITE structure. Because of the experimental design, such variations of profit splits can be attributed to structural effects. According to the NCB model, they reflect that, apart from unequal numbers of actors and ties, the structures under consideration are associated with different distributions of network control-while the KITE network has more nodes and links than the 3-BRANCH structure, the distribution of network control is more unequal in the latter than in the former. As a consequence, the profit differentiation in the 3-BRANCH network will be more extreme than in the KITE structure. ${ }^{16}$ Notice that, if the empirically observed means of profit points are taken as measuring rods, the NCB model closely predicts the profit splits in both networks.

The acceptable fit of the NCB model is not limited to the empirical findings reported in Table 1. This becomes clear if one follows Burke (1997) and combines the data of Skvoretz and Willer (1993) with those of Lovaglia et al. (1995) as well as Skvoretz and Fararo (1992). ${ }^{17}$ Specifically, we calculate the means of all the experimental results for

\footnotetext{
15 All theories fail to predict that the structural position B in the STEM network apparently gets a larger profit in the match with $\mathrm{C}$ than in the relation with $\mathrm{A}$. It should be noted, however, that the mean of profit points associated with the B:C relation in Table 1 is, in comparison to the empirical results for all other matches, based on a low number of exchanges and associated with a large standard error. Skvoretz and Lovaglia (1995) discuss, among other things, the relatively rare occurrence of B:C exchanges in the STEM structure.

16 The NCB model predicts a maximum differentiation of profits in specific networks only. For structures with equally valued and substitutable relations between distinct positions, Eq. (9) implies that the profit division approaches maximum differentiation if and only if there is a sufficiently large number of network members and mutual ties, and the advantaged actor has full control over his relations. An example is the negatively connected 100-BRANCH structure in which 100 actors solely depend on actor $i$ for the split of an identical value $v$. This straightforward extension of the 3-BRANCH logic from Fig. 1 is characterized by $m=100, n=101, c_{i}=1$, and $c_{j}=0.01$ for all $j \neq i$ such that $x_{i j}=p_{i j} v=0.999 v$ determines $i$ 's profit share in the pure rival connected relation with $j$. Notice that, while the predicted profit division in small networks (i.e., structures with few actors and/or ties) deviates from maximum differentiation, the condition $c_{i}=1$ always ensures a relatively extreme profit differentiation in favor of $i$ if the focus is on structures with negative connections.

17 The combination of these data neglects, however, that the studies vary, despite similar designs, in terms of the experimental results reported. For example, while Lovaglia et al. (1995) report simple arithmetic means of profit
} 
each of the four network structures: 4-Line B:A 13.7; STEM B:A 15.2, B:C 15.9; KiTE B:A 13.2; 3-BRANCH B:A 20.7. A systematic comparison of these means with the theoretical predictions listed in Table 1 shows that the NCB model produces the smallest deviations $(\mathrm{AD}=1.14 ; \mathrm{MD}=0.60)$. Again, the $\mathrm{NCB}$ predictions are relatively close to the average observations for the networks under consideration. It is to be asked whether this conclusion may be extended to other networks and types of connections.

\subsection{Power distributions}

Negotiated distributions of exchange profits reflect power inequalities due to different structural positions. Usually, the power of one position over another is measured by the proportion of value obtained by the former position in the match with the latter. This procedure is compatible with the NCB approach. Alternatively, actor $i$ 's systemwide power share $p_{i}$ may be obtained via adding up $i$ 's relative bargaining power for all matches and standardizing the result by $m$, the number of mutual ties in the respective network. Formally,

$$
p_{i}=\frac{1}{m} \sum_{k=1}^{n} p_{i k} \quad \text { for all } i
$$

such that $\sum_{k=1}^{n} p_{k}=1$. Table 2 reports relevant predictions of the NCB model for the negatively connected networks 5-LINE and 31-STAR as well as for the positively connected 5-LiNe structure (see again Fig. 1 for graphs, relational matrices, and control vectors).

Using experimental observations for each network (Cook et al., 1983; Markovsky et al., 1988, 1997; Yamagishi et al., 1988) as reference points, Table 2 contrasts NCB-predictions with those from Yamaguchi's (1996) power model (i.e., the other theoretical approach dealing with both negatively and positively connected relations). For the comparison of the theories' predictive accuracy, we use the average weighted Euclidean distance between observed and predicted systemwide profit levels associated with distinct positions in any particular network as the "goodness-of-fit" measure. This "Weighted Deviation" (WD) takes into account that specific network positions may exist several times in the structure under consideration. To demonstrate its computation, let us take a look at the NCB-predictions for the 5-LINE with substitutable connections. As displayed in Table 2, NCB assigns the systemwide power levels $p_{\mathrm{C}}=0.1649, p_{\mathrm{B}}=0.3351$, and $p_{\mathrm{A}}=0.0825$ to the positions $\mathrm{C}$, $\mathrm{B}$, and A, respectively. ${ }^{18}$ The latter are compared with the average observations (Table 2) for this structure. Since the 5-Line consists of just one position C, but two positions A and $\mathrm{B}$, the sum of squared deviations is $(0.1564-0.1649)^{2}+2 \times(0.3275-0.3351)^{2}+$

splits in network relations from the last rounds of experiments only, Skvoretz and Willer (1993) estimate means of profit points via a constrained regression technique from all experimental observations.

18 The calculation of the systemwide power levels may be illustrated as well. Take, for example, position B in the negatively connected 5-LiNE network. Because of the structural features and the degrees of network control displayed in Fig. 1, position $\mathrm{B}$ has the relative bargaining power $p_{\mathrm{BA}}=0.6701=p_{\mathrm{BC}}$ in matches with positions A and C, respectively. Positions in the 5-Line structure are connected by four mutual ties $(m=4)$. Evaluating Eq. (11), B's systemwide proportion of power is then $p_{\mathrm{B}}=(1 / 4) \times(0.6701+0.6701)=0.3351$. 
Table 2

Power of positions in selected exchange networks

\begin{tabular}{|c|c|c|c|c|}
\hline \multirow[t]{2}{*}{ Network } & \multicolumn{3}{|c|}{ Network positions } & \multirow[t]{2}{*}{ WD } \\
\hline & $\mathrm{C}$ & $\mathrm{B}$ & A & \\
\hline \multicolumn{5}{|l|}{ 5-LINE, NEGATIVE CONNECTIONS } \\
\hline Predicted (NCB) & 0.1649 & 0.3351 & 0.0825 & $0.0043^{\mathrm{a}}$ \\
\hline Observed (Cook et al., 1983) & 0.2097 & 0.3059 & 0.0892 & - \\
\hline Observed (Cook et al., 1983, corrected) ${ }^{\mathrm{b}}$ & 0.1436 & 0.3303 & 0.0978 & - \\
\hline Observed (Markovsky et al., 1997) & 0.1159 & 0.3464 & 0.0957 & - \\
\hline Mean of observations & 0.1564 & 0.3275 & 0.0942 & - \\
\hline \multicolumn{5}{|l|}{ Predicted (Yamaguchi, 1996) } \\
\hline Parameter choice $s=\infty$ & 0.1667 & 0.2500 & 0.1667 & $0.0301^{\mathrm{a}}$ \\
\hline Parameter choice $s=8$ & 0.1764 & 0.2500 & 0.1618 & $0.0294^{\mathrm{a}}$ \\
\hline \multicolumn{5}{|l|}{ 31-STAR, NEGATIVE CONNECTIONS } \\
\hline Predicted (NCB) & 0.1923 & 0.2051 & 0.0641 & $0.0188^{\mathrm{a}}$ \\
\hline Observed $\left(\right.$ Skvoretz and Fararo, 1992) ${ }^{\mathrm{c}}$ & 0.1021 & 0.2583 & 0.0410 & - \\
\hline Observed (Markovsky et al., 1988, 1997) & 0.0635 & 0.2355 & 0.0767 & - \\
\hline Mean of observations & 0.0828 & 0.2469 & 0.0589 & - \\
\hline \multicolumn{5}{|l|}{ Predicted (Yamaguchi, 1996) } \\
\hline Parameter choice $s=\infty$ & 0.1250 & 0.1667 & 0.1250 & $0.0264^{\mathrm{a}}$ \\
\hline Parameter choice $s=8$ & 0.1383 & 0.1667 & 0.1205 & $0.0262^{\mathrm{a}}$ \\
\hline \multicolumn{5}{|l|}{ 5-LINE, POSITIVE CONNECTIONS } \\
\hline Predicted $(\mathrm{NCB})$ & 0.3264 & 0.1736 & 0.1632 & 0.0071 \\
\hline Observed (Yamagishi et al., 1988) ${ }^{\mathrm{d}}$ & 0.3133 & 0.1931 & 0.1503 & - \\
\hline \multicolumn{5}{|l|}{ Predicted (Yamaguchi, 1996) } \\
\hline Parameter choice $s=-\infty$ & 0.5000 & 0.2500 & 0.0000 & 0.0588 \\
\hline Parameter choice $s=-8$ & 0.4961 & 0.2500 & 0.0020 & 0.0579 \\
\hline
\end{tabular}

Notes: WD = Weighted Deviation (the average weighted Euclidean Distance between observed and predicted systemwide profit shares, where the weights refer to the number of indicated positions in the network). NCB = Network Control Bargaining model. Applying Yamaguchi's theory requires a specification of the elasticity of substitution $(s)$.

a The calculation of WD refers to the mean of observations.

b Corrections by Markovsky et al. (1997, Table 1).

c The original values have been re-scaled to sum to 1.0.

d Following Yamaguchi (1996), Markovsky et al. (1997), the result from the first trial block (see Table 1 in Yamagishi et al., 1988, p. 843) was considered as an extreme outlier and therefore excluded.

$2 \times(0.0942-0.0825)^{2}=0.000462$. Taking the square root and dividing the result by the number of comparisons (i.e., $\sqrt{0.000462} / 5$ ) yields the reported WD of 0.0043 .

Together with the other WD values from the last column of Table 2, this result indicates that the NCB-predictions are closer to the experimental observations than predictions from Yamaguchi's model for different parameter choices. In particular, the NCB model performs well in regard to the only published experiment on a positively connected exchange network (Yamagishi et al., 1988). These authors focused on the flow through exchange of two different goods in a 5-LINE structure, with one flowing from the left-hand side and the other flowing from the right-hand side of the network. Positively connected relations were ensured by incentives - the extent to which an actor acquired both goods determined his payoff. Following Yamaguchi (1996) and Markovsky et al. (1997), Table 2 reports the 
experimental observations in standardized form. The NCB predictions for the power levels of the three positions result from combining the network features $(m=4, n=5)$ and the degrees of network control (cf., Fig. 1) in Eq. (10) and inserting the relative bargaining powers into Eq. (11). They correspond closely with the empirical evidence.

In comparison to its predictive performance for the 5-LINE structures, the NCB model gives a relatively inaccurate prediction for the power distribution in the 31-STAR network. Table 2 lists the NCB predictions and informs about the relevant observations of Skvoretz and Fararo (1992) and Markovsky et al. (1988, 1997). While the NCB predictions for the power levels of the positions $\mathrm{A}$ and $\mathrm{B}$ are reasonably close to the empirically observed means, the prediction for C's power is too large. But, as far as we know the literature, neither theory does better with respect to point predictions for all positions in this particular structure.

In sum, the NCB model predicts the effects of network embeddedness for exchange profits at least as well as the best fitting published theories. Like any other model, however, the NCB theory rests on several strong premises. It thus is reasonable to conclude with a brief discussion of possible extensions of the model.

\section{Discussion}

In this paper, we have presented an alternative approach to the study of specific networks - the focus was on simple robust structures of bargaining and exchange. In accordance with other theories, our approach reflects the idea that rational actors take advantage of their structural positions in negotiations. Contrary to other sociological models, however, we have combined the generalized Nash bargaining solution from game theory with the assumption that both relational features and network positions affect exchange outcomes. It was shown that the resulting predictions for profit splits and power distributions correspond closely with experimental results obtained by Cook et al. (1983), Lovaglia et al. (1995), Markovsky et al. (1988), Simpson and Willer (1999), Skvoretz and Fararo (1992), Skvoretz and Willer (1993) as well as Yamagishi et al. (1988).

It has to be emphasized, however, that the approach rests on strong premises. The latter ensure, on the one hand, a close correspondence between the theoretical model and the artificial conditions in laboratory research on exchange networks. They prevent, on the other hand, that the current model captures all relevant aspects of real negotiation and exchange systems. It thus is reasonable to discuss briefly important limitations, available extensions, and possible modifications of the approach.

A first shortcoming of the model is its focus on the effects network positions and relational features have for exchange outcomes. More specifically, position holders are assumed to be relatively homogenous. A similar postulate characterizes most sociological work on exchange networks. However, interindividual heterogeneity with respect to, say, age or gender may matter for negotiation results as well (e.g., Eckel and Grossman, 2001; Solnick, 2001). A more realistic model version therefore could start from the idea that bargaining powers depend on both individual and structural variables.

A second limitation of the approach is its behavioral postulate. According to the model, each actor is a selfish profit maximizer. This postulate excludes fairness considerations 
and/or effects of relative standing in terms of profits. According to experimental research from different disciplines, such additional motivations seem to play an important role in specific settings (see, for a review, Rabin, 1998). The recent progress in behavioral game theory (e.g., Bolton and Ockenfels, 2000; Camerer, 1997, 2003) therefore may provide a helpful starting point for their incorporation into the analysis of exchange networks.

A third shortcoming of the model is its neglect of potential side-effects of ongoing exchanges in dyads. While this feature is typical to many theories of exchange networks and their laboratory tests, it is surely not a realistic one. According to Lawler and Yoon's (1996) experiments, for instance, people who engage in repeated exchanges may form attachments and make commitments. Such an increase in relational cohesion can stabilize established network relations and, possibly, change long run outcomes. These aspects of durable exchange relations deserve attention because of their importance in everyday life. Their analysis requires, from a theoretical perspective, a dynamic modeling approach. Here, one could follow Muthoo (1999) who studies, among other things, an infinitely repeated bargaining game and its differences to the static bargaining scenario.

A fourth limitation of the approach seems to be its relatively restricted domain-in its current version, the model concerns only those exchange networks which are robust and simple. Due to its focus on robust structures, the above approach does not predict trading patterns between positions if there are substitutable relations such that actors have to select actual exchange partners from a larger set of potential exchange partners. Such predictions seem to be particularly desirable if one follows Cook and Whitmeyer's (1992) suggestion and advocates a theoretical approach that uses exchange theory to explain network structure. As Braun and Gautschi (2004a) show, however, predictions of exchange patterns become feasible if the current model is extended for the analysis of non-robust structures. It is thus possible to specify necessary and sufficient conditions for which exchange structures will differ from a given bargaining network.

These conditions hold true for any model of negotiated exchanges which generates, based upon the postulate of self-interested behavior, point predictions for profit divisions. Therefore, they are also relevant for a generalization of the current model (Braun and Gautschi, 2004b). The general model has been developed for the analysis of complex exchange structures. It thus is not limited to predictions on either substitutable or complementary network relations each of which concerns the partitioning of an identical surplus or value between a specific pair of actors on the basis of the same restrictions. ${ }^{19}$ From this perspective, the current model refers to an experimentally important scenario which may be seen as a special case of a much broader approach.

\footnotetext{
19 Braun and Gautschi (2004b) show that the general model explains the partitioning of cakes of unequal sizes in different bargaining relations. Also, it can handle situations in which actors face different exchange restrictions (e.g., completion of different number of exchanges per round). Moreover, while the above model allows for either substitutable or complementary relations only, the general model does not exclude mixed relations across the network. That is, in contrast to its initial version, the general model is suited for the analysis of a situation in which, say, actor $i$ faces substitutable relations only, whereas $i$ 's bargaining partner $j$ classifies their relation as complementary to his other relations.
} 


\section{Acknowledgment}

We thank Vincent Buskens, Andreas Diekmann, Winand Emons, Axel Franzen, Werner Raub, Chris Snijders, Tom Snijders, Jeroen Weesie, Rolf Ziegler, and three anonymous reviewers for their helpful suggestions and comments.

\section{References}

Bienenstock, E.J., Bonacich, P., 1992. The core as a solution to negatively connected exchange networks. Social Networks 14, 231-243.

Bienenstock, E.J., Bonacich, P., 1993. Game theory models for exchange networks: experimental results. Sociological Perspectives 36, 117-135.

Bienenstock, E.J., Bonacich, P., 1997. Network exchange as a cooperative game. Rationality and Society 9, 37-65.

Binmore, K.G., 1985. Bargaining and coalitions. In: Roth, A.E. (Ed.), Game-Theoretic Models of Bargaining. Cambridge University Press, Cambridge, pp. 269-304.

Binmore, K.G., 1987. Nash bargaining theory II. In: Binmore, K.G., Dasgupta, P. (Eds.), The Economics of Bargaining. Blackwell, Oxford,. pp. 61-76.

Binmore, K.G., 1992. Fun and Games: A Text on Game Theory. D.C. Heath and Company, Lexington, MA.

Binmore, K.G., 1998. Game Theory and the Social Contract, vol. 2, Just Playing. MIT Press, Cambridge.

Bolton, G.E., Ockenfels, A., 2000. ERC: a theory of equity, reciprocity, and competition. American Economic Review 90, 166-193.

Bonacich, P., 1998. A behavioral foundation for a structural theory of power in exchange networks. Social Psychology Quarterly 61, 185-198.

Bonacich, P., 1999. An algebraic theory of strong power in negatively connected networks. Journal of Mathematical Sociology 23, 203-224.

Bonacich, P., Bienenstock, E.J., 1995. When rationality fails: unstable exchange networks with empty cores. Rationality and Society 7, 293-320.

Bonacich, P., Friedkin, N.E., 1998. Unequally valued exchange relations. Social Psychology Quarterly 61, 160171.

Braun, N., Gautschi, T., 2004a. Who Exchanges With Whom? A Theory of Exchange Ties and its Application to Simple Networks. Working Paper, University of Munich and University of Bern.

Braun, N., Gautschi, T., 2004b. Who Gets How Much in Which Relation? A Flexible Theory of Profit Splits in Complex Networks. Working Paper, University of Munich and University of Bern.

Burke, P.J., 1997. An identity model for network exchange. American Sociological Review 62, 134-150.

Camerer, C.F., 1997. Progress in behavioral game theory. Journal of Economic Perspectives 11, 167-188.

Camerer, C.F., 2003. Behavioral Game Theory. Experiments in Strategic Interaction. Princeton University Press, Princeton.

Coleman, J.S., 1973. The Mathematics of Collective Action. Aldine, Chicago.

Coleman, J.S., 1990. Foundations of Social Theory. The Belknap Press of Harvard University Press, Cambridge.

Cook, K.S., Emerson, R.M., 1978. Power, equity, and commitment in exchange networks. American Sociological Review 43, 721-739.

Cook, K.S., Emerson, R.M., Gillmore, M.R., Yamagishi, T., 1983. The distribution of power in exchange networks: theory and experimental results. American Journal of Sociology 89, 275-305.

Cook, K.S., Whitmeyer, J.M., 1992. Two approaches to social structure: exchange theory and network analysis. Annual Review of Sociology 18, 109-127.

Eckel, C., Grossman, P., 2001. Chivalry and solidarity in ultimatum games. Economic Inquiry 39, $171-188$.

Emerson, R.M., 1972. Exchange Theory. Part II: Exchange Relations and Networks. pp. 58-87 in Sociological Theories in Progress, Vol. 2, edited by J. Berger, M. Zelditch, and B. Anderson. Boston: HoughtonMifflin.

Feld, S.L., 1991. Why your friends have more friends than you do. American Journal of Sociology 96, 14641477. 
Friedkin, N.E., 1986. A formal theory of social power. Journal of Mathematical Sociology 12, 103126.

Friedkin, N.E., 1992. An expected value model of social power: predictions for selected exchange networks. Social Networks 14, 213-229.

Friedkin, N.E., 1993. An Expected Value Model of Social Exchange Outcomes. pp. 163-193 in Advances in Group Processes, Vol. 10, edited by E.J. Lawler, B. Markovsky, K. Heimer and J. O’Brien. Greenwich, CT: JAI Press.

Friedkin, N.E., 1995. The incidence of exchange networks. Social Psychology Quarterly 58, 213-221.

Lawler, E.J., Yoon, J., 1996. Commitment in exchange relations: test of a theory of relational cohesion. American Sociological Review 61, 89-108.

Lovaglia, M.J., Skvoretz, J., Willer, D., Markovsky, B., 1995. Negotiated exchanges in social networks. Social Forces 74, 123-155.

Markovsky, B., Willer, D., Patton, T., 1988. Power relations in exchange networks. American Sociological Review 53, 220-236.

Markovsky, B., Willer, D., Patton, T., 1990. Theory, evidence and intuition (reply to Yamagishi and Cook, 1990). American Sociological Review 55, 300-305.

Markovsky, B., Skvoretz, J., Willer, D., Lovaglia, M.J., Erger, J., 1993. The seeds of weak power: an extension of network exchange theory. American Sociological Review 58, 197-209.

Markovsky, B., Willer, D., Simpson, B., Lovaglia, M.J., 1997. Power in exchange networks: critique of a new theory. (comment on Yamaguchi, 1996). American Sociological Review 62, 833-837.

Molm, L.D., Peterson, G., Takahashi, N., 2001. The value of exchange. Social Forces 80, 159-184.

Muthoo, A., 1999. Bargaining Theory with Applications. Cambridge University Press, Cambridge.

Nash, J.F., 1950. The bargaining problem. Econometrica 18, 155-162.

Nash, J.F., 1951. Non-cooperative games. Annals of Mathematics 54, 286-295.

Nash, J.F., 1953. Two-person cooperative games. Econometrica 21, 128-140.

Osborne, M.J., Rubinstein, A., 1990. Bargaining and Markets. Academic Press, San Diego.

Perry, M., Reny, P.J., 1993. A non-cooperative bargaining model with strategically timed offers. Journal of Economic Theory 59, 50-77.

Rabin, M., 1998. Psychology and economics. Journal of Economic Literature 36, 11-46.

Rubinstein, A., 1982. Perfect equilibrium in a bargaining model. Econometrica 50, 97-109.

Simpson, B., Willer, D., 1999. A new method for finding power structures. In: Willer, D. (Ed.), Network Exchange Theory. Praeger, Westport, CT, pp. 270-284.

Skvoretz, J., Fararo, T.J., 1992. Power and network exchange: an essay toward theoretical unification. Social Networks 14, 325-344.

Skvoretz, J., Lovaglia, M.J., 1995. Who exchanges with whom: structural determinants of exchange frequency in negotiated exchange networks. Social Psychology Quarterly 58, 163-177.

Skvoretz, J., Willer, D., 1991. Power in exchange networks: setting and structural variations. Social Psychology Quarterly 54, 224-238.

Skvoretz, J., Willer, D., 1993. Exclusion and power: a test of four theories of power in exchange networks. American Sociological Review 58, 801-818.

Solnick, S.J., 2001. Gender differences in the ultimatum game. Economic Inquiry 39, 189-200.

Thye, S.R., Lovaglia, M.J., Markovsky, B., 1997. Responses to social exchange and social exclusion in networks. Social Forces 75, 1031-1049.

Willer, D. (Ed.), 1999. Network exchange theory. Praeger, Westport, CT.

Yamagishi, T., Cook, K.S., 1990. Power relations in exchange networks: a comment on 'Network Exchange Theory'. American Sociological Review 55, 297-300.

Yamagishi, T., Cook, K.S., 1992. Power in exchange networks: a power-dependence formulation. Social Networks 14, 245-266.

Yamagishi, T., Gillmore, M.R., Cook, K.S., 1988. Network connections and the distribution of power in exchange networks. American Journal of Sociology 93, 833-851.

Yamaguchi, K., 1996. Power in networks of substitutable and complementary exchange relations: a rational choice model and an analysis of power centralization. American Sociological Review 61, 308332 . 
Yamaguchi, K., 1997. The logic of the new theory and misrepresentations of the logic. (Reply to Markovsky et al., 1997). American Sociological Review 62, 838-841.

Yamaguchi, K., 2000. Power in mixed exchange networks: a rational choice model. Social Networks 22, 93-121. Young, H.P., 1993. An evolutionary model of bargaining. Journal of Economic Theory 59, 145-168.

Young, H.P., 2001. Individual Strategy and Social Structure. An Evolutionary Theory of Institutions. Princeton University Press, Princeton. 